\title{
The microbiological impact of pulsed xenon ultraviolet disinfection on resistant bacteria, bacterial spore and fungi and viruses
}

\author{
Mark Stibich, ${ }^{1 *}$ Julie Stachowiak' \\ ${ }^{1}$ Xenex Disinfection Services, Texas, USA \\ *Corresponding author, email: stibich@gmail.com
}

Pathogens can persist in the patient care environment and cause the risk of transmission to patients. Pulsed xenon ultraviolet (PX-UV) is increasingly being used to disinfect patient rooms, operating rooms and other areas. Data on the impact of PX-UV on resistant bacteria, bacterial spores, fungi, viruses and the Ebola virus are lacking in the literature. Laboratory data are presented in this paper on the log reductions observed after the exposure of PX-UV to a variety of organisms in a laboratory setting.

Keywords: hospital-acquired infections, HAls, organisms, pathogens, pulsed xenon ultraviolet, PX-UV

\section{Introduction}

Hospital-acquired infections(HAls) arealeading cause ofmortality and morbidity, and cost to healthcare systems. The cumulative incidence of HAls following various surgical procedures on the African continent ranges from 10-31\%, markedly higher than that in high-income countries. ${ }^{1}$ Increasingly, antimicrobial resistant organisms are being seen in the hospital setting. $A$ portion of these infections can be attributed to the environment, as many common hospital pathogens can survive for weeks to months in the patient care environment. ${ }^{2}$ The inability of manual cleaning to effectively disinfect patient care areas has been demonstrated in studies in the USA setting. ${ }^{3}$

Ultraviolet (UV) room disinfection is becoming more common in hospitals. Over 300 hospitals in the USA alone use pulsed xenon (PX) ultraviolet (PX-UV) devices for infection control purposes, and these have been linked to a reduction in HAI rates of more than 50\%. ${ }^{4-10}$ However, independent laboratory data on the germicidal impact of PX-UV on common hospital pathogens commonly seen in hospital applications has not been published in the scientific literature. Data from two well-established, independent laboratories are presented in this article, and the impact of PX-UV devices on significant hospital pathogens demonstrated.

\section{Method}

Testing for all organisms, except the Ebola virus and Bacillus antrhracis, was conducted at the National Center for Biotechnology, part of the Spanish National Research Council (Consejo Superior de Investigaciones Científicas), the largest public research institute in Spain. The Eboba virus and B. anthracis, testing was conducted at the Texas Biomedical Research Institute, which contains a full suit Biosafety Level 4 (BSL-4) laboratory, with clearance from the US Centers for Disease
Control and Prevention (CDC) with respect to handling a range of BSL-4 agents, including the Ebola virus.

\section{Pulsed xenon ultraviolet device}

The PX-UV device, a patented device which produces highintensity germicidal light using a pulsing xenon lamp, and which is fully commercialised for use in hospital and other settings, was used as a source in all of the tests. The PX-UV device has been described in detail elsewhere in the literature. ${ }^{11}$

\section{Laboratory methods}

A separate section for each pathogen or group of pathogens is provided.

\section{Gram-negative and gram-positive bacteria and fungi}

Isolates of the following organisms were obtained by donation from hospital networks in Spain:

- Extended-spectrum beta lactamase-producing Klebsiella pneumoniae.

- Pseudomonas aeruginosa, which produces carbapenemase.

- Acinetobacter baumannii resistant to antibiotics.

- Escherichia coli carbapenemase.

- Methicillin-resistant Staphylococcus aureus.

- Aspergillus niger.

Prior culture and growth of the bacteria and fungus was carried out in a Luria broth liquid culture medium at $37^{\circ} \mathrm{C}$ until concentration ranges of $10^{6}-10^{2}$ colony-forming units (CFUs) per millilitre were obtained, depending on the type of organism. The suspensions obtained were diluted in saline solution, and subsequently agitated to ensure their homogeneity, then placed in empty $\mathrm{p}-100$ Petri dishes. The inocula were spread with sterile glass-inoculating loops. The inocula were then allowed to dry 
at ambient temperatures under the sterile laminar flow of the biosafety cabinet.

Two control Petri dishes and two Petri dishes treated in identical conditions were prepared for each organism, and placed on a mount at an angle of 45 degrees from horizontal, at approximately one metre in height, and at a distance of one metre from the PXUV device. The exposure time was five minutes. The control Petri dishes remained covered and the treated ones remained open during exposure. A curve of exposure times was carried out at $0,5,10,15$ and 30 minutes for $A$. niger. Each exposure time was performed in triplicate.

After exposure, the control and treated Petri dishes were incubated at $37^{\circ} \mathrm{C}$ for $24-72$ hours, depending on the degree of growth of the colonies. The results were obtained by comparing the number of colonies in the treated and control samples.

The protocol was repeated on three different days, on three different degrees of culture growth, i.e. in biological triplicate. Therefore, there were six final figures for the treated and control samples.

\section{Gram-positive bacterial spores}

The following Gram-positive bacterial spores were used from commercially available sources:

- Geobacillus stearothermophilus ProSpore spore kit (106 spores), in $4 \mathrm{ml}$ ampoules with culture medium and growth indicator.

- B. atrophaeus spore kit $\left(10^{7} / \mathrm{ml}\right)$, in a $10 \mathrm{ml}$ vial, with culture medium and growth indicator.

The preparations of $G$. stearothermophilus and B. atrophaeus were carried out by adding an inoculum of $1 \times 10^{6}$ to $5 \times 10^{6}$ spores to each empty $\mathrm{p}-100$ Petri dish. The inocula were allowed to dry at an ambient temperature inside the biosafety cabinet under the flow of sterile laminar air for 1-2 hours. The inocula were spread in the central area of each Petri dish, using a sterile glass-inoculating loop in order to facilitate drying.

A pair of control Petri dishes and a pair of treated Petri dishes were prepared under identical conditions for each bacteria. Bacteria were exposed to PX-UV in the same manner as that previously described. After exposure to UV light, replications of the treated and control Petri dishes were carried out using

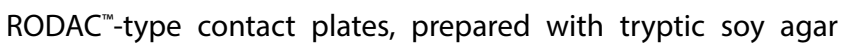
culture medium. The RODAC $C^{\mathrm{m}}$ plates were incubated at $37^{\circ} \mathrm{C}$ for 24-72 hours, depending on the degree of growth of the colonies. The results were obtained by comparing the number of colonies in the treated and control samples. The protocol was repeated four times in order to obtain the final data.

\section{Bacillus anthracis}

A similar experiment was performed with live B. anthracis spores. Care was taken to ensure that all bacteria were in the hardto-kill spore form. PX-UV exposure times were 15, 30, 45 and 60 minutes at a distance of one metre and a height of one metre.

\section{Middle East respiratory syndrome coronavirus}

Viral suspensions, with an approximate titre of between $10^{5}$ and $10^{6} \mathrm{CFU} / \mathrm{ml}$, were prepared in a Dulbecco's modified eagle medium (DMEM) culture, supplemented with $5 \%$ foetal bovine serum (FBS). The viral suspensions were applied in the form of a small drop of $500 \mu \mathrm{i}$ in the centre of $\mathrm{p}-100$ Petri dishes which had previously been prepared by applying a sheet of Parafilm plastic film in order to reduce the surface tension of the drop so that it remained more exposed. Further optimisation was created in a follow-up experiment by replacing the $500 \mu$ i drop with 20 drops of $5 \mu$ i per Petri dish in order to reduce the shielding from the UV light produced by the liquid in the sample.

The exposure conditions were similar to those already described for the bacteria, with the exception that the liquid suspensions were placed directly on the working surface of the biosafety cabinet. A pair of control Petri dishes and a pair of treated Petri dishes were prepared under identical conditions for each exposure. After carrying out exposure to UV light, titration of the control and treated viral suspensions was performed, and their infectivity assessed in susceptible Vero E6 (African green monkey) cells through tests for the formation of lysis plaques. The viral titres in the samples were treated for differing periods and to determine the reduction in viral viability that exposure to PXUV produced in Middle East respiratory syndrome coronavirus (MERS-CoV). The aforementioned protocol was repeated on the basis of three different prior growths of cultures, i.e. in biological triplicate.

\section{Vaccinia virus and infectious bursal disease virus}

An identical protocol to that described for the MERS-CoV virus was applied to the procedure carried out for vaccinia virus and infectious bursal disease virus (IBDV). The growth and titration of the vaccinia virus was performed through the experimental infection of susceptible BSC-40 cells of the Cercopithecus aethiops primate. The growth and titration of IBDV was performed by using the QM7 cellular line, derived from a fibrosarcoma in the Japanese quail (Coturnix japonica).

The only difference from the previously described protocol was that initially $100 \mu \mathrm{i}$ drops were prepared for the IBDV virus, instead of $500 \mu$ i. An attempt was made to optimise the protocol for both viruses by reducing the volume of the samples to $5 \mu \mathrm{i}$ droplets. Three tests for each virus were performed, each of these consisting of two control Petri dishes and two treated ones.

\section{Vesicular stomatitis virus}

The growth and titration of the vesicular stomatitis virus (VSV) was performed through the experimental infection of susceptible BSC-40 cells of the C. aethiops primate. The cultures were prepared and kept in a liquid DMEM medium, supplemented with $10 \%$ FBS. Infection of the cells in the DMEM medium was then performed, and they were subsequently kept in the DMEM medium with $2 \%$ FBS. The viral suspensions obtained in the DMEM medium with $2 \%$ FBS had a titre of approximately $10^{6}$ lysis plaque-forming units (PFUs) per millilitre. These suspensions 
Table 1: Independent laboratory testing results, involving pulsed xenon ultraviolet

\begin{tabular}{|c|c|c|c|c|c|}
\hline Organism & $\begin{array}{l}\text { Cycle time } \\
\text { (minutes) }\end{array}$ & Distance (metres) & $\begin{array}{l}\text { Pathogen count } \\
\text { before disinfection }\end{array}$ & $\begin{array}{l}\text { Pathogen count } \\
\text { after disinfection }\end{array}$ & $\begin{array}{c}\text { Logarithmic } \\
\text { reduction } \\
\text { measured }\end{array}$ \\
\hline Klebsiella pneumoniae & 5 & 1 & $1.88 \mathrm{E}+10$ & $3.42 \mathrm{E}+01$ & 8.74 \\
\hline Pseudomonas aeruginosa & 5 & 1 & $9.12 \mathrm{E}+10$ & $4.30 \mathrm{E}+01$ & 9.33 \\
\hline Acinetobacter baumannii & 5 & 1 & $6.07 \mathrm{E}+10$ & $4.67 \mathrm{E}+01$ & 9.11 \\
\hline Escherichia coli & 5 & 1 & $3.32 \mathrm{E}+10$ & $2.68 \mathrm{E}+01$ & 9.09 \\
\hline Staphylococcus aureus & 5 & 1 & $4.52 \mathrm{E}+10$ & $3.47 \mathrm{E}+01$ & 9.11 \\
\hline Geobacillus stearothermophilus & 5 & 1 & $1.69 \mathrm{E}+06$ & $2.57 \mathrm{E}+02$ & 3.82 \\
\hline Bacillus atrophaeus & 5 & 1 & $4.89 \mathrm{E}+05$ & $2.51 \mathrm{E}+02$ & 3.29 \\
\hline Aspergillus niger & 5 & 1 & $1.07 \mathrm{E}+03$ & $5.02 \mathrm{E}+02$ & 0.33 \\
\hline Aspergillus niger & 10 & 1 & $1.07 \mathrm{E}+03$ & $1.37 \mathrm{E}+02$ & 0.89 \\
\hline Aspergillus niger & 15 & 1 & $1.07 \mathrm{E}+03$ & $6.03 \mathrm{E}+01$ & 1.25 \\
\hline Aspergillus niger & 30 & 1 & $1.07 \mathrm{E}+03$ & 4.10E+01 & 1.61 \\
\hline MERS-CoV (liquid) & 5 & 1 & $4.13 E+04$ & $2.17 \mathrm{E}+04$ & 1.54 \\
\hline Vaccinia virus (liquid) & 5 & 1 & $4.98 \mathrm{E}+06$ & $1.63 \mathrm{E}+05$ & 1.38 \\
\hline IBDV (liquid) & 5 & 1 & $2.41 \mathrm{E}+07$ & $3.33 \mathrm{E}+06$ & 0.86 \\
\hline VSV (dried) & 5 & 1 & $2.60 \mathrm{E}+05$ & $0.00 \mathrm{E}+00$ & All \\
\hline Bacillus anthracis & 15 & 1 & $4.5 \mathrm{E}+03$ & $0.00 \mathrm{E}+00$ & All \\
\hline Ebola virus & 1 & 1 & $1.85 \mathrm{E}+07$ & $0.00 \mathrm{E}+00$ & All \\
\hline
\end{tabular}

IBDV: infectious bursal disease virus, MERS-CoV: Middle East respiratory syndrome coronavirus, VSV: vesicular stomatitis virus

were agitated to ensure their homogeneity, and inoculated into p-100 Petri dishes. The inoculum was spread with the inoculating loops. Thus, the prepared Petri dishes were allowed to dry under the sterile laminar flow of the biosafety cabinet at an ambient temperature for approximately 30 minutes. PX-UV exposure was performed using the same curve of times, and under identical conditions to those used for A. niger. Post-exposure viral control and treatment samples were recovered, and treated with the addition of DMEM culture with $2 \%$ FBS to each Petri dish. The infectivity of each sample was then assessed in susceptible BSC40 cells through lysis plaque-formation tests. The viral titres were expressed in PFUs/ml.

\section{Live Ebola virus}

To test the antiviral affects of PX-UV exposure on the Ebola virus, $20 \mu \mathrm{i}$ of virus was dried onto to a chamber slide. After drying, the samples were positioned vertically at a distance of one metre, and exposed to UV light generated by the Xenex robot for various lengths of time, i.e. 1, 2, 5 and 10 minutes. The virus was resuspended and harvested from the slide, and the remaining infectious virus was quantified by plaque assay.

\section{Results}

The study's independent laboratory testing results, involving PX-UV, are detailed in Table 1.

\section{Vegetative bacteria}

Log reductions ranging from 8.74-9.33 CFUs/ml were observed for vegetative bacteria after five minutes of PX-UV exposure at one metre.

\section{Bacterial spores}

Log reductions ranging from 3.29-3.82 CFUs/ml were observed for bacterial spores after five minutes of PX-UV exposure at one metre.

\section{Bacillus anthracis}

Growth was not observed for B. anthracis (detect threshold of a $3 \mathrm{CFU} / \mathrm{ml}$ log reduction) after 15 minutes of PX-UV exposure at one metre.

\section{Fungi}

Log reductions ranging from $0.33-1.61 \mathrm{CFUs} / \mathrm{ml}$ for fungi were observed after $5,10,15$, and 30 minutes of exposure to PX-UV at one metre.

\section{Viruses}

Log reductions ranging from 0.86-1.54 PFUs/ml were observed when the inocula was in liquid form, and log reductions of $\geq 5.00$ were observed for the dried virus after five minutes of PX-UV exposure at one metre.

\section{Ebola virus}

Growth was not observed (detection threshold of a 4 PFUs $/ \mathrm{ml}$ log reduction) for the live Ebola virus after one minute of PX-UV exposure at one metre.

\section{Discussion}

There is a contamination level of $\leq 500$ organisms $/ \mathrm{cm}^{2}$ in a typical hospital environment after cleaning. ${ }^{12}$ The level of disinfection for vegetative spores in a five-minute cycle achieved using 
the PX-UV device (8.7-9.1 log reduction) exceeds that which is necessary in the hospital environment. While the disinfection achieved was lower for the spore-forming organisms (3.29-3.82), it still exceeded the likely level of contamination in a hospital and patient care environment.

Additional time was required for disinfection of the fungus, $A$. niger, in order to reach a level of $1.61 \mathrm{CFU} / \mathrm{ml}$ log reduction at 30 minutes. A. niger is more resistant to UV light than vegetative organisms as it is a multicellular eukaryotic microbe, so these results were not unexpected.

Logarithmic reductions achieved for MERS-CoV, the vaccinia vaccinia virus and IBDV, were 0.58, 1.66 and $1.21 \mathrm{PFUs} / \mathrm{ml}$, respectively. This lower reduction can be explained by the liquid nature of the virus preparations, which necessitated placing them horizontally on the surface for more indirect exposure, as well as the potential UV shielding caused by the viral suspension itself. To address these confounders, VSV was used as a virus sample which could be dried on a surface for an extended period and still retain its infectivity. This allowed the samples to be placed at 45 degrees for more direct exposure. Complete elimination of any detectable virus was noted in this case. It should be noted that viral contaminants would be in the dry form in most environmental situations in which PX-UV would be used.

The tests demonstrated that there was total elimination of the organisms at one and 15 minutes, respectively, for both the live Ebola virus and the B. anthracis. This indicates the potential of the PX-UV system to be deployed in an outbreak or biopreparedness manner.

The tests used here demonstrate the influence of laboratory methods over the reported effectiveness of technologies. For example, a large difference between wet and dry viral inocula was noted. A number of variables have been reported to influence the laboratory results in other research, including humidity, temperature, the smoothness of surfaces, protein loading, reflectivity, distance and other variables. While proof-of-concept data have been demonstrated in laboratory studies, readers are encouraged to seek data on the impact of a technology, such as PX-UV, in a real-world setting. ${ }^{11,13-16}$

Lastly, the organisms chosen for these tests represent organisms which were causing, or which would have the potential to cause, significant public health threats, including extended-spectrum beta lactamase-producing organisms, carbapenemaseproducing organisms, resistant strains of $A$. baumannii and S. aureus, the Ebola virus and B. anthracis. The magnitude of the log reduction observed from the use of PX-UV against each of these organisms indicated that PX-UV disinfection played a role in preventing transmission of these organisms, and thereby in reducing the associated morbidity and mortality. Furthermore, by decreasing the probability of transmission of these organisms through a contaminated environment, PX-UV can contribute to efforts to address antimicrobial resistance by reducing the number of infections, and therefore extending the effectiveness of antibiotics by reducing demand for them.

\section{Declaration}

Funding for testing at the National Center for Biotechnology was provided by a third party, while funding for testing at the Texas Biomedical Research Institute was provided by the manufacturer of the PX-UV device (Xenex Disinfection Services, San Antonio, USA).

\section{References}

1. Bagheri Nejad S, Allegranzi B, Syed SB, et al. Health-care-associated infection in Africa: a systematic review. Bull World Health Organ. 2011;89(10):757-765.

2. Chemaly RF, Simmons S, Dale C Jr., et al. The role of the healthcare environment in the spread of multidrug-resistant organisms: update on current best practices for containment. Ther Adv Infect Dis. 2014;2(3-4):79-90.

3. Carling PC, Parry MF, Von Beheren SM, Healthcare Environmental Hygiene Study Group. Identifying opportunities to enhance environmental cleaning in 23 acute care hospitals. Infect Control Hosp Epidemiol. 2008;29(1):1-7.

4. Levin J, Riley LS, Parrish C, et al. The effect of portable pulsed xenon ultraviolet light after terminal cleaning on hospital-associated Clostridium difficile infection in a community hospital. Am J Infect Control. 2013;41(8):746-748.

5. Haas JP, Menz J, Dusza S, Montecalvo MA. Implementation and impact of ultraviolet environmental disinfection in an acute care setting. Am J Infect Control. 2014;42(6):586-590.

6. Nagaraja $A$, Visintainer $P$, Haas JP, et al. Clostridium difficile infections before and during use of ultraviolet disinfection. Am J Infect Control. 2015; pii: S0196-6553(15)00514-3.

7. Fornwalt $L$, Ennis $D$, Stibich M. Influence of a total joint infection control bundle on surgical site infection rates. Am J Infect Control. 2016;44(2):239-241.

8. Miller $\mathrm{R}$, Simmons $\mathrm{S}$, Dale $\mathrm{C}$, et al. Utilization and impact of a pulsed-xenon ultraviolet room disinfection system and multidisciplinary care team on Clostridium difficile in a long-term acute care facility. Am J Infect Control. 2015;43(12):1350-1353.

9. Simmons $\mathrm{S}$, Morgan $\mathrm{M}$, Hopkins $\mathrm{T}$, et al. Impact of a multi-hospital intervention utilising screening, hand hygiene education and pulsed xenon ultraviolet (PX-UV) on the rate of hospital associated meticillin resistant Staphylococcus aureus infection. Journal of Infection Prevention. 2013; 14(5):172-174.

10. Vianna PG, Dale CR, Simmons $S$, et al. Impact of pulsed xenon ultraviolet light on hospital-acquired infection rates in a community hospital. Am J Infect Control. 2016;44(3):299-303.

11. Jinadatha C, Quezada R, Huber TW, et al. Evaluation of a pulsed-xenon ultraviolet room disinfection device for impact on contamination levels of methicillinresistant Staphylococcus aureus. BMC Infect Dis. 2014;141:187.

12. Otter Ja, Yezli S, French GL. The role played by contaminated surfaces in the transmission of nosocomial pathogens. Infect Control Hosp Epidemiol. 2011;32(7):687-699.

13. Ghantoji SS, Stibich M, Stachowiak J, et al. Non-inferiority of pulsed xenon ultraviolet light versus bleach versus for reducing environmental Clostridium difficile contamination on high-touch surfaces in Clostridium difficile isolation rooms. J Med Microbiol. 2015. pii: jmm.0.000004.

14. Stibich M, Stachowiak J, Tanner B, et al. Evaluation of a pulsed-xenon ultraviolet room disinfection device for impact on hospital operations and microbial reduction. Infect Control Hosp Epidemiol. 2011;32(3):286-288.

15. Jinadatha C, Villamaria FC, Ganachari-Mallappa N, et al. Can pulsed xenon ultraviolet light systems disinfect aerobic bacteria in the absence of manual disinfection? Am J Infect Control. 2015;43(4):415-417.

16. Jinadatha C, Villamaria FC, Restrepo Ml, et al. Is the pulsed xenon ultraviolet light no-touch disinfection system effective on methicillin-resistant Staphylococcus aureus in the absence of manual cleaning? Am J Infect Control. 2015;43(8):878-881. 